\title{
L-asparaginase-based regimen as a first-line treatment for newly diagnosed nasal type extranodal natural killer cell/T-cell lymphoma
}

\author{
SHANSHAN BU ${ }^{1 *}$, FANGFANG YUAN $^{1 *}$, XUDONG WEI $^{1}$, QINGSONG YIN ${ }^{1}$, YUFU LI ${ }^{1}$, RUIHUA MI $^{1}$, \\ HAIPING YANG ${ }^{2}$, HONGYI LI ${ }^{3}$, SHOUBEI GE ${ }^{4}$, YANYAN LIU ${ }^{1}$ and YONGPING SONG ${ }^{1}$ \\ ${ }^{1}$ Department of Hematology, Tumor Hospital of Zhengzhou University, Zhengzhou, Henan 450008; \\ ${ }^{2}$ Department of Hematology, First Affiliated Hospital of Henan University of Science and Technology, \\ Luoyang, Henan 471003; ${ }^{3}$ Department of Hematology, Xinzheng People's Hospital, Xinxiang, Henan 453000; \\ ${ }^{4}$ Department of Hematology, Second Jiaozuo People's Hospital, Jiaozuo, Henan 522000, P.R. China
}

Received December 12, 2014; Accepted December 15, 2015

DOI: $10.3892 / \mathrm{etm} .2016 .3249$

\begin{abstract}
The aim of the present study was to compare the efficacy of an L-asparaginase-based regimen and a CHOP regimen followed by radiotherapy as first-line treatments for newly diagnosed nasal type extranodal natural killer cell/T-cell lymphoma (ENKTL). A total of 69 patients received the CHOP regimen as the first-line treatment and 112 patients received the L-asparaginase-based regimen. All patients received radical radiotherapy following two cycles of chemotherapy. The overall response rates of the L-asparaginase-based and CHOP treatment groups were 90.18 and $72.46 \%$, respectively $(\mathrm{P}=0.002)$. The one, two, and five-year overall survival (OS) rates and progression-free survival (PFS) rates of the L-asparaginase group were 96.0, 88.3, 65.1, 94.2, 79.8 and $50.0 \%$, respectively. The one, two, and five-year OS and PFS rates of the CHOP group were 82.6, 61.9, 25.8, 63.8, 44.0 and $21.0 \%$, respectively $(\mathrm{P}<0.001)$. Compared with $\mathrm{CHOP}$ treatment, L-asparaginase-based chemotherapy combined with radiotherapy was a safe and highly effective treatment for newly diagnosed ENKTL.
\end{abstract}

\section{Introduction}

Extranodal natural killer (NK) cell/T-cell lymphoma (ENKTL) is a type of non-Hodgkin's lymphoma that presents significantly different distributions patterns according to population

Correspondence to: Professor Xudong Wei, Department of Hematology, Tumor Hospital of Zhengzhou University, 127 Dongming Road, Zhengzhou, Henan 450008, P.R. China E-mail: xudongwei@zzu.edu.cn

\section{${ }^{*}$ Contributed equally}

Key words: extranodal natural killer cell/T-cell lymphoma, CHOP, L-asparaginase, treatment and geography, and is relatively common in Asia and South America $(1,2)$. The incidence of patients with lymphoma is as high as $11 \%$ in China (3). NK/T-cell lymphomas usually occur in middle-aged patients, and their features are characterized by localized disease in approximately two-thirds of patients, along with frequent adjacent tissue invasion, a high frequency of 'B' symptoms, despite apparently limited disease, and rare bone marrow involvement (4-6). In addition, ENKTL is highly invasive, resistant to conventional chemotherapy, highly malignant, associated with short survival time and rapid clinical progression, and has a relatively poor prognosis (7-9).

ENKTL is thought to arise from NK cells or occasionally from a subset of $\gamma \delta \mathrm{d}$ or $\alpha \beta$ cytotoxic T-cells, and is strongly associated with Epstein-Barr virus infection $(10,11)$. The ENKTL phenotype is characterized by the expression of cytoplasmic CD $3 \varepsilon$ in the absence of surface CD3, T-cell receptor expression, or T-cell receptor gene rearrangement, as well as an activated cytotoxic profile with expression of perforin, granzyme B, TIA-1, and frequent CD56 expression $(12,13)$.

As ENKTL is rare, and prospective group studies are limited, no standard treatment regimen is currently available. Early NK/T-cell lymphoma is sensitive to radiotherapy if confined to the nasal cavity; however, recurrence at the primary site or distant sites occurred in $50 \%$ of patients who received radiotherapy, with a five-year survival rate of 29.8-66\% (14-17). Since the multidrug resistance (MDR) gene is highly expressed in ENKTL tumor cells, the tumors are insensitive to conventional chemotherapy regimens (such as CHOP) that are applied to other pathological types of non-Hodgkin's lymphoma (18). Asparaginase is not regulated by the MDR gene, and numerous studies have demonstrated that the application of asparaginase to relapsed or refractory ENKTL induced promising responses and high survival rates (19-22). Few clinical studies on asparaginase-based regimens as first-line treatments for newly diagnosed ENKTL are available $(22,23)$, and, to the best of our knowledge, no previous studies have compared the short-term efficacy and long-term survival impacts of asparaginase and CHOP treatment regimens in patients with ENKTL. Therefore, the present study investigated the effects of asparaginase in 
patients with previously untreated ENKTL. The clinical characteristics of 181 patients with newly-diagnosed pathologically ENKTL were retrospectively analyzed. The patients were divided into CHOP treatment regimen and asparaginase-based chemotherapy groups according to the administered treatment regimen. Short-term efficacy, long-term survival, and safety were compared in the two groups and the results are reported herein.

\section{Materials and methods}

Clinical data. A total of 181 patients with newly diagnosed ENKTL received either CHOP treatment or L-asparaginase-based chemotherapy along with radiotherapy between October 2003 and June 2013 at the Henan Tumor Hospital, First Affiliated Hospital of Henan University of Science and Technology (Luoyang, China), the Xinzheng City People's Hospital (Xinzheng, China), and the Jiaozuo City Second People's Hospital (Jiaozuo, China). Of these patients, 69 were included in the CHOP treatment group and 112 were included in the L-asparaginase treatment group. All patients were diagnosed via imaging studies and pathological analyses. Differences in the main clinical characteristics between the two groups of patients were not statistically significant $(\mathrm{P}>0.05)$, as shown in Table I.

Prognostic factors. The International Prognostic Index (IPI) clinical tool was used to predict the prognosis of patients (24). IPI factors include: Age, $>60$ years; serum lactate dehydrogenase (LDH) level above normal; performance status, 2-4; stage of disease, III or IV; and extranodal involvement, $>1$ site (24). In addition, the gender, B-symptoms (including unexplained fever, $>10 \%$ weight loss or sweating), Eastern Cooperative Oncology Group performance status and primary anatomic sites of lymphomatous involvement for all patients were evaluated for their potential prognostic importance. The serum LDH and $\beta_{2}$-microglobulin levels were analyzed using an automated biochemical analyzer (Modular P800; Hitachi, Ltd., Tokyo, Japan), and the expression of Ki67 in ENKTL tumor samples were assessed by immunohistochemistry. Briefly, the tumor samples were cut into sections using a microtome (Leica RM2235; Leica Microsystems GmbH, Wetzlar, Germany), followed by incubation with mouse anti-Ki67 monoclonal antibody (1:200; cat. no. M7240; Dako, Glostrup, Denmark), and then ready-to-use EnVision reagent (cat. no. K5007; Dako). Subsequently, positive cells (yellow/tan color) were counted in 10 fields of view under a microscope (Olympus IX81; Olympus Corporation, Tokyo, Japan). Phosphate-buffered saline was used as a negative control.

Treatment. The CHOP treatment regimen included $750 \mathrm{mg} / \mathrm{m}^{2}\left(\mathrm{~d}_{1}\right)$ cyclophosphamide (Baxter Oncology $\mathrm{GmbH}$, Halle, Germany), $50 \mathrm{mg} / \mathrm{m}^{2}\left(\mathrm{~d}_{1}\right)$ adriamycin (Pfizer, New York, USA), $1.4 \mathrm{mg} / \mathrm{m}^{2}\left(\mathrm{~d}_{1}\right)$ vincristine (Zhejiang Hisun Pharmaceutical, Co., Ltd., Taizhou, China) and $40 \mathrm{mg} / \mathrm{m}^{2}$ $\left(\mathrm{d}_{1-5}\right)$ prednisone (Zhejiang Xianju Pharmaceutical Co., Ltd., Taizhou, China), which was administered to 69 patients. L-asparaginase (Guangzhou Baiyun Shan Ming Xing Pharmaceutical, Co., Ltd., Guangzhou, China) treatment was given to 112 patients. The patients who received $\mathrm{L}$-asparaginase treatment were subdivided into the following treatment groups: CHOP-L (65 patients), VLP (22 patients), COP-L (10 patients), or L-asparaginase alone (15 patients). The patients in the CHOP-L group received the entire CHOP treatment regimen, whereas the patients in the VLP group received the vincristine and prednisone only, and the patients in the COP-L group received the cyclophosphamide, vincristine and prednisone only. All patients received $6,000 \mathrm{U} / \mathrm{m}^{2}\left(\mathrm{~d}_{1-7}\right) \mathrm{L}$-asparaginase and the other drugs at the reference doses described for the CHOP treatment. The patients who responded positively to an L-asparaginase skin test (25 patients), which was indicated by the presence of erythemas or wheals, were treated with 2,500 U/m $\mathrm{m}^{2}$ pegaspargase (Jiang Su Heng Rui Medicine, Co., Ltd., Lianyungang, China). During chemotherapy, the heart, liver and kidneys were protected by intravenous injection with $5 \mathrm{mg}$ tropisetron hydrochloride (Jiang Su Heng Rui Medicine, Co., Ltd.) $30 \mathrm{~min}$ prior to chemotherapy, hydration (250-300 $\mathrm{ml} / \mathrm{m}^{2} \mathrm{H}_{2} \mathrm{O}$ ) and $1.25 \%$ sodium bicarbonate (Tianjin Pharmaceuticals Group Co., Ltd., Tianjin, China) intravenous injection. Following chemotherapy, patients with leukocytopenia (white blood cells count, $<4.0 \times 10^{9} / 1$ ) were treated with granulocyte colony-stimulating factor (Harbin Pharmaceutical Group Bioengineering, Co., Ltd., Harbin, China) to elevate their white blood cell counts, patients with anaemia were injected with red blood cells, and patients with low platelets were transfused with platelets (both Henan Red Cross Blood Centre, Zhengzhou, China). All patients underwent involved-field radiation therapy (TrueBeam ${ }^{\mathrm{TM}}$ Radiotherapy System; Varian Medical Systems, Inc., Palo Alto, CA, USA) following two cycles of chemotherapy. Three-dimensional radiotherapy counting was performed with a 6-8 MV photon ray at a median dose of 52 Gy (range, 40-60 Gy) and was administered in fractionated doses of 2 Gy five times/week. The radiotherapy target covered the edge of the lesion and the infiltration. Subsequent chemotherapy continued until completion following radiotherapy. All patients provided signed written-informed consent prior to treatment.

Evaluation of short-term efficacy and adverse reactions. All patients underwent at least six cycles of chemotherapy combined with radiotherapy. Following two cycles of chemotherapy and the entire treatment regimen, the efficacies of the treatments in all patients were evaluated by a physical examination, B-ultrasound and computed tomography (CT; GE LightSpeed Pro 32; GE Healthcare Life Sciences, Chalfont, UK) or positron emission/CT (GE Discovery STE 16; GE Healthcare Life Sciences). Clinical efficacy was assessed according to World Health Organization (WHO) criteria (25), which classify responses as complete remission (CR), partial remission (PR), stable disease and progressive disease. The overall response rate (ORR) was calculated as CR + PR. Based on the WHO evaluation criteria for adverse reactions, the adverse reactions were divided into 0-IV degrees of severity. Toxicity assessments were conducted at the end of each chemotherapy cycle.

Evaluation of survival. Overall survival (OS) was defined as the time between the date of diagnosis and the date on which the patient succumbed to the disease or the end of the follow-up period. Progression-free survival (PFS) was defined as the time between the date of diagnosis and the date of tumor 
Table I. Clinical characteristics of patients with newly diagnosed ENKTL.

\begin{tabular}{|c|c|c|c|}
\hline Characteristic & CHOP & L-asparaginase & P-value \\
\hline Gender & & & 0.685 \\
\hline Male & 47 & 73 & \\
\hline Female & 22 & 39 & \\
\hline Age, years & & & 0.571 \\
\hline$\leq 60$ & 59 & 99 & \\
\hline$>60$ & 10 & 13 & \\
\hline Ann Arbor stage & & & 0.89 \\
\hline $\mathrm{I} / \mathrm{II}$ & 58 & 95 & \\
\hline III/IV & 11 & 17 & \\
\hline IPI score & & & 0.679 \\
\hline $0-1$ & 52 & 92 & \\
\hline$\geq 2$ & 17 & 20 & \\
\hline ECOG performance status & & & 0.88 \\
\hline $0-1$ & 67 & 109 & \\
\hline$\geq 2$ & 2 & 3 & \\
\hline B symptoms & & & 0.229 \\
\hline Yes & 30 & 59 & \\
\hline No & 39 & 53 & \\
\hline ENKTL subtype & & & 0.639 \\
\hline UNKTL & 66 & 107 & \\
\hline EUNKTL & 3 & 5 & \\
\hline Bony perforation & 18 & 28 & 0.87 \\
\hline Elevated serum LDH (>245 IU/1) & 42 & 53 & 0.076 \\
\hline Elevated $\beta_{2}$-microglobulin $(>2.2 \mathrm{U} / \mathrm{l})$ & 52 & 76 & 0.281 \\
\hline Leukocytopenia $\left(<4.0 \times 10^{9} / 1\right)$ & 15 & 26 & 0.818 \\
\hline Haemoglobin $(<110 \mathrm{~g} / \mathrm{l})$ & 14 & 21 & 0.799 \\
\hline $\mathrm{CD} 56^{+}$ & 57 & 97 & 0.463 \\
\hline $\mathrm{EBV}^{+}$ & 43 & 63 & 0.421 \\
\hline Ki67 expression (median) & 60 & 60 & 0.846 \\
\hline
\end{tabular}

Table II. Response assessments in the two treatment groups at various time points.

\begin{tabular}{|c|c|c|c|c|c|}
\hline \multirow[b]{2}{*}{ Group } & \multirow[b]{2}{*}{$\mathrm{N}$} & \multicolumn{2}{|c|}{ Following the second cycle } & \multicolumn{2}{|c|}{ Following all cycles and radiation } \\
\hline & & $\mathrm{CR}$ & ORR & $\mathrm{CR}$ & ORR \\
\hline CHOP & 69 & $10(14.5 \%)$ & $32(46.4 \%)$ & $29(42.03 \%)$ & $50(72.46 \%)$ \\
\hline L-asp & 112 & $38(31.3 \%)$ & $76(67.9 \%)$ & $72(64.28 \%)$ & $101(90.18 \%)$ \\
\hline P-value & & 0.011 & 0.004 & 0.003 & 0.002 \\
\hline
\end{tabular}

$\mathrm{CR}$, complete remission; ORR, overall response rate.

progression/relapse, the date on which the patient succumbed to the disease, or the end of the follow-up period. For patients who were lost to follow-up, survival ended at the time of the last follow-up.
Statistical analysis. Statistical analysis was conducted with SPSS 18.0 software (SSPS, Inc., Chicago, IL, USA). Categorical variables were compared between the groups using a $\chi^{2}$ test, and continuous variables were compared between groups using a 
Table III. Clinical characteristics and response rates following CHOP and L-asparaginase-based treatment regimens followed by radiation.

\begin{tabular}{|c|c|c|c|c|c|c|}
\hline \multirow[b]{2}{*}{ Characteristic } & \multicolumn{3}{|c|}{$\mathrm{CHOP}$} & \multicolumn{3}{|c|}{ L-asparaginase } \\
\hline & $\mathrm{N}$ & ORR & P-value & $\mathrm{N}$ & ORR & P-value \\
\hline Gender & & & 0.973 & & & 1.000 \\
\hline Male & 47 & 34 & & 73 & 66 & \\
\hline Female & 22 & 16 & & 39 & 35 & \\
\hline Age & & & 0.000 & & & 0.225 \\
\hline$\leq 60$ & 59 & 48 & & 99 & 91 & \\
\hline$>60$ & 10 & 2 & & 13 & 10 & \\
\hline Ann Arbor stage & & & 0.000 & & & 0.012 \\
\hline $\mathrm{I} / \mathrm{II}$ & 58 & 48 & & 95 & 89 & \\
\hline III/IV & 11 & 2 & & 17 & 12 & \\
\hline IPI score & & & 0.000 & & & 0.036 \\
\hline $0-1$ & 52 & 46 & & 92 & 86 & \\
\hline$\geq 2$ & 17 & 4 & & 20 & 15 & \\
\hline ECOG performance status & & & 0.073 & & & 0.025 \\
\hline $0-1$ & 67 & 50 & & 109 & 100 & \\
\hline$\geq 2$ & 2 & 0 & & 3 & 1 & \\
\hline B symptoms & & & 0.344 & & & 0.896 \\
\hline Yes & 30 & 20 & & 53 & 48 & \\
\hline No & 39 & 30 & & 59 & 53 & \\
\hline ENKTL subtype & & & 0.182 & & & 0.006 \\
\hline UNKTL & 66 & 49 & & 107 & 99 & \\
\hline EUNKTL & 3 & 1 & & 5 & 2 & \\
\hline Bony perforation & 18 & 12 & 0.739 & 28 & 26 & 0.855 \\
\hline Elevated LDH level & 42 & 28 & 0.179 & 53 & 45 & 0.076 \\
\hline Elevated $\beta_{2}$-microglobulin & 52 & 38 & 1.00 & 76 & 68 & 0.981 \\
\hline Leukocytopenia & 15 & 10 & 0.809 & 26 & 20 & 0.027 \\
\hline Haemoglobin & 14 & 7 & 0.076 & 21 & 18 & 0.722 \\
\hline $\mathrm{CD}_{56} 6^{+}$ & 57 & 41 & 1.000 & 97 & 88 & 0.980 \\
\hline $\mathrm{EBV}^{+}$ & 43 & 29 & 0.23 & 63 & 55 & 0.401 \\
\hline $\mathrm{Ki} 67^{*}$ & & & 0.919 & & & 0.075 \\
\hline Low & 37 & 27 & & 73 & 69 & \\
\hline High & 32 & 23 & & 39 & 32 & \\
\hline Pegaspargase replacement & - & - & - & 25 & 22 & 0.973 \\
\hline
\end{tabular}

IPI, international prognostic index; ECOG, Eastern Cooperative Oncology Group; ENKTL, extranodal natural killer cell/T-cell lymphoma; UNKTL, upper aerodigestive tract natural killer cell/T-cell lymphoma; EUNKTL, non-upper aerodigestive tract natural killer cell/T-cell lymphoma; LDH, lactate dehydrogenase; EBV, Epstein-Barr virus; ORR, overall response rate.

t-test for independent samples. Kaplan-Meier survival analysis was applied to calculate the patient survival rates. The survival rates were compared between groups using a log-rank test. Variables with $\mathrm{P}<0.05$ were included in the Cox proportional hazards regression model for multivariate analysis. $\mathrm{P}<0.05$ was considered to indicate a statistically significant result.

\section{Results}

Short-term efficacy and long-term survival. Treatment efficacies were evaluated in the 181 patients, and the overall efficacies in the two treatment groups are shown in Table II. The 69 patients in the CHOP treatment group included 10 cases of CR and 22 cases of PR for an ORR of $46.4 \%$ following two cycles of chemotherapy; 29 cases of CR and 21 cases of PR for an ORR of $72.46 \%$ was shown at the end of the treatment. The $\chi^{2}$ test results (Table III) demonstrated that among the various clinical factors, patient age, clinical stage, and IPI score significantly affected the ORR $(\mathrm{P}<0.001)$ at the end of the treatment period. The 112 patients in the asparaginase group included 38 cases of CR and 38 cases of PR for an ORR of $67.9 \%$ following two cycles of chemotherapy, and 72 cases 
Table IV. Survival data of the two groups.

\begin{tabular}{|c|c|c|c|c|c|c|}
\hline \multirow[b]{2}{*}{ Group } & \multicolumn{3}{|c|}{ OS rate $(\%)$} & \multicolumn{3}{|c|}{ PFS rate $(\%)$} \\
\hline & One-year & Two-year & Five-year & One-year & Two-year & Five-year \\
\hline CHOP & 82.6 & 61.9 & 28.4 & 63.8 & 44.0 & 21.0 \\
\hline L-asp & 96.0 & 88.3 & 65.1 & 94.2 & 79.8 & 50.0 \\
\hline P-value & 0.00 & 0.00 & 0.00 & 0.00 & 0.00 & 0.00 \\
\hline
\end{tabular}

OS, overall survival; PFS, progression-free survival; L-asp, L-asparaginase.

Table V. Univariate analysis of prognostic factors.

\begin{tabular}{|c|c|c|c|c|}
\hline \multirow[b]{2}{*}{ Factor } & \multicolumn{2}{|c|}{ CHOP } & \multicolumn{2}{|c|}{ L-asparaginase } \\
\hline & OS & PFS & OS & PFS \\
\hline Gender & 0.556 & 0.611 & 0.332 & 0.212 \\
\hline Age & 0.000 & 0.000 & 0.027 & 0.038 \\
\hline Ann Arbor stage & 0.000 & 0.000 & 0.000 & 0.000 \\
\hline IPI score & 0.000 & 0.000 & 0.005 & 0.018 \\
\hline ECOG performance status & 0.000 & 0.000 & 0.000 & 0.000 \\
\hline B symptoms & 0.575 & 0.439 & 0.593 & 0.575 \\
\hline ENKTL subtype & 0.000 & 0.000 & 0.000 & 0.000 \\
\hline Bony perforation & 0.314 & 0.248 & 0.973 & 0.898 \\
\hline Elevated LDH & 0.025 & 0.008 & 0.014 & 0.001 \\
\hline Elevated $\beta_{2}-\mathrm{MG}$ & 0.300 & 0.356 & 0.550 & 0.242 \\
\hline Leukopenia & 0.034 & 0.006 & 0.006 & 0.020 \\
\hline Haemoglobin & 0.295 & 0.134 & 0.959 & 0.077 \\
\hline CD56 & 0.982 & 0.896 & 0.717 & 0.422 \\
\hline EBV & 0.217 & 0.268 & 0.493 & 0.418 \\
\hline Ki67 & 0.024 & 0.035 & 0.001 & 0.001 \\
\hline Early efficacy & 0.000 & 0.000 & 0.000 & 0.000 \\
\hline Pegaspargase replacement & - & - & 0.191 & 0.638 \\
\hline
\end{tabular}
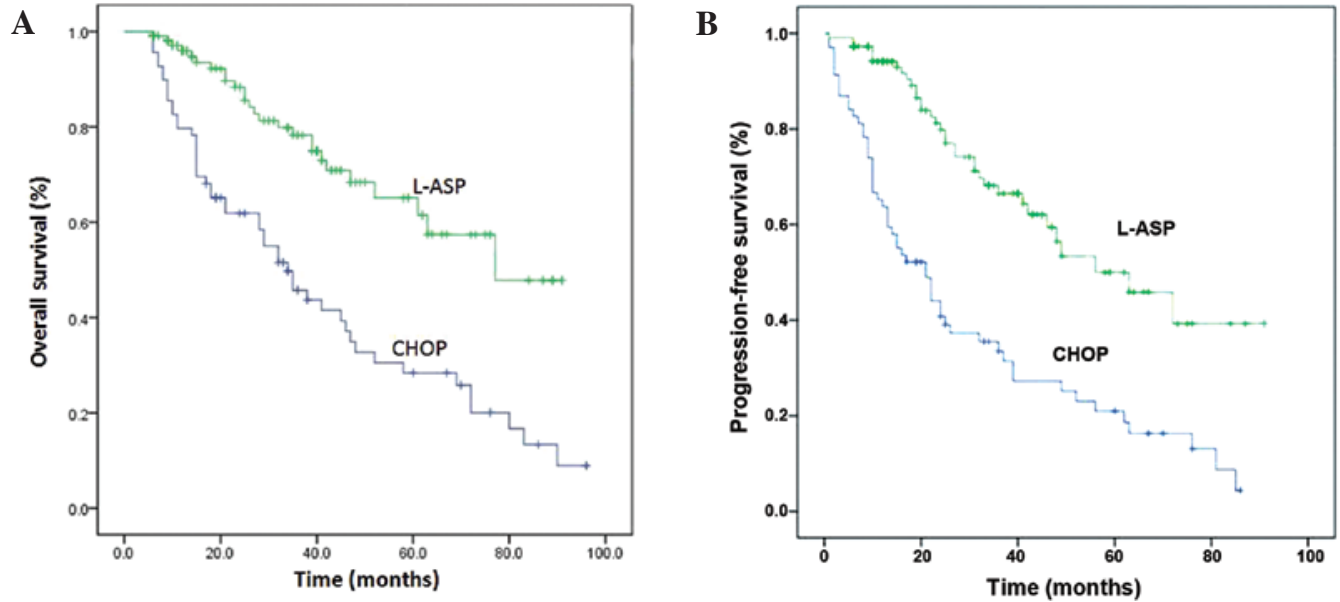

Figure 1. Kaplan-Meier survival curves for all patients with extranodal natural killer cell/T-cell lymphoma treated with CHOP or L-asparaginase-based regimens combined with radiation. (A) Overall survival. (B) Progression-free survival. 
Table VI. Cox proportional hazard regression analysis for the CHOP and L-asparaginase treatment groups.

\begin{tabular}{|c|c|c|c|c|c|c|c|c|}
\hline \multirow[b]{2}{*}{ Survival } & \multicolumn{4}{|c|}{ CHOP (95\% CI) } & \multicolumn{4}{|c|}{ L-asparaginase $(95 \% \mathrm{CI})$} \\
\hline & RR & Lower & Upper & P-value & $\mathrm{RR}$ & Lower & Upper & P-value \\
\hline \multicolumn{9}{|l|}{ OS } \\
\hline Early efficacy & 6.596 & 2.365 & 18.397 & 0.000 & 8.760 & 2.879 & 26.657 & $<0.001$ \\
\hline Ann Arbor stage & 2.003 & 0.372 & 10.771 & 0.418 & 10.588 & 2.553 & 43.910 & 0.001 \\
\hline Ki67 & 1.578 & 0.843 & 2.954 & 0.154 & 6.517 & 2.165 & 19.615 & 0.001 \\
\hline $\mathrm{LDH}$ & 1.330 & 0.632 & 2.800 & 0.452 & 3.525 & 1.092 & 11.373 & 0.035 \\
\hline \multicolumn{9}{|l|}{ PFS } \\
\hline Early efficacy & 7.144 & 2.853 & 17.890 & 0.000 & 4.093 & 1.635 & 10.245 & 0.003 \\
\hline ENKTL subtype & 8.597 & 1.677 & 44.085 & 0.010 & 4.962 & 0.621 & 39.655 & 0.131 \\
\hline Ki67 & 1.438 & 0.758 & 2.727 & 0.266 & 3.554 & 1.582 & 7.984 & 0.002 \\
\hline Ann Arbor stage & 1.580 & 0.300 & 8.330 & 0.590 & 7.405 & 2.045 & 26.811 & 0.002 \\
\hline Age & 5.260 & 1.351 & 20.480 & 0.017 & 5.480 & 0.595 & 50.433 & 0.133 \\
\hline $\mathrm{LDH}$ & 1.348 & 0.646 & 2.811 & 0.426 & 3.554 & 1.582 & 7.984 & 0.001 \\
\hline
\end{tabular}

RR, risk ratio; 95\% CI, 95\% confidence interval; OS, overall survival; LDH, lactate dehydrogenase; PFS, progression-free survival; ENKTL, extranodal natural killer cell/T-cell lymphoma.

Table VII. Toxicity profiles of the CHOP and L-asparaginase treatment groups.

\begin{tabular}{|c|c|c|c|c|c|c|}
\hline \multirow[b]{2}{*}{ Toxicity } & \multicolumn{2}{|c|}{$\mathrm{CHOP}$} & \multicolumn{2}{|c|}{ L-asparaginase } & \multirow[b]{2}{*}{$\chi^{2}$} & \multirow[b]{2}{*}{ P-value } \\
\hline & I-II & III-IV & I-II & III-IV & & \\
\hline Leukopenia & $36(52.2)$ & $13(18.8)$ & $59(52.7)$ & $25(22.3)$ & 0.348 & 0.555 \\
\hline Anaemia & $13(18.8)$ & $2(2.9)$ & $24(21.4)$ & $5(4.5)$ & 0.400 & 0.527 \\
\hline Thrombocytopenia & 8 (11.6) & $1(1.4)$ & $13(11.6)$ & $2(1.8)$ & 0.005 & 0.946 \\
\hline Increase in ALT/AST & $11(15.9)$ & $3(4.3)$ & $31(27.7)$ & $5(4.5)$ & 3.000 & 0.083 \\
\hline Increase in bilirubin & 8 (11.6) & $2(2.9)$ & $25(22.3)$ & $4(3.6)$ & 3.283 & 0.070 \\
\hline Increase in creatinine & $10(14.5)$ & 0 & $16(14.3)$ & 0 & 0.001 & 0.969 \\
\hline Increase in BUN & $6(8.7)$ & 0 & $11(9.8)$ & 0 & 0.064 & 0.801 \\
\hline Anaphylaxis & $3(4.3)$ & 0 & $29(25.9)$ & 0 & 13.618 & $<0.001$ \\
\hline Nausea, vomiting & $41(59.4)$ & 3 & $76(67.9)$ & $10(8.9)$ & 1.647 & 0.199 \\
\hline Infection & $15(21.7)$ & & $23(20.5)$ & & 0.037 & 0.847 \\
\hline Reduction in FIB & $5(7.2)$ & & $68(60.7)$ & & 50.721 & $<0.001$ \\
\hline
\end{tabular}

ALT/AST, alanine aminotransferase/aspartate aminotransferase; BUN, blood urea nitrogen; FIB, fibrinogen.

of CR and 29 cases of PR for an ORR of $90.18 \%$ at the end of the treatment period. Among the various clinical factors, clinical staging, IPI score, ECOG score, primary lesion site, and leukocytopenia affected the ORR $(\mathrm{P}<0.05)$.

The patients were followed-up until 31 October 2013, with a median follow-up time of 29 months (range, 6-96 months). A total of 10 cases were lost to follow-up. In the CHOP treatment group, the median OS duration was 34 months, the median PFS duration was 21 months, the one, two, and five-year OS rates were $82.6,61.9$ and $28.4 \%$, respectively, and the one, two, and five-year PFS rates were 63.8, 44.0 and $21.0 \%$, respectively (Table IV,Fig. 1A and B). Univariate analysis demonstrated that patient age, clinical staging, IPI score, ECOG score, primary lesion site, LDH levels, leukocytopenia, Ki67 levels and early treatment response significantly affected patient OS and PFS $(\mathrm{P}<0.05)$. Other factors such as gender, B symptoms, and $\beta_{2}$-microglobulin had no impact on the OS and PFS ( $P>0.05$; Table V). Multivariate analysis demonstrated that early treatment response was an independent predictor of OS $(\mathrm{P}<0.001)$, whereas primary lesion site, early treatment response, and age were independent predictors of PFS ( $\mathrm{P}=0.010, \mathrm{P}<0.001$, and $\mathrm{P}=0.017$, respectively; Table VI). In the asparaginase treatment group, the median OS duration was 77 months, the median PFS duration was 56 months, the one, two, and five-year OS rates were $96.0,88.3$ and $65.1 \%$, respectively, and the one, two, and five-year PFS rates were 94.2, 79.8 and 50\%, respectively. Univariate analysis demonstrated that patient age, clinical stage, IPI score, ECOG score, primary lesion site, LDH level, 
leukocytopenia, Ki67 level, and early treatment response affected patient OS and PFS $(\mathrm{P}<0.05)$; other factors such as gender, $B$ symptoms, and $\beta_{2}$-microglobulin had no impact on OS and PFS ( $\mathrm{P}>0.05)$. Multivariate analysis demonstrated that early treatment, clinical staging, LDH levels, and Ki67 levels were independent predictors of OS and PFS $(\mathrm{P}<0.001$, $\mathrm{P}=0.001,0.035$ and 0.001 , and $\mathrm{P}=0.011,0.002,0.002$ and 0.02 , respectively).

Adverse reactions. The adverse reactions observed in the patients in the two groups are shown in Table VII. The primary adverse reactions to chemotherapy included bone marrow suppression, gastrointestinal reactions, infections, and liver dysfunction, the majority of which were rapidly relieved following symptomatic treatment. In the asparaginase treatment group, 68 cases $(60.7 \%)$ showed a statistically significant reduction in fibrinogen levels, as compared with the CHOP treatment group $(\mathrm{P}<0.001)$. Associated bleeding and thrombotic events occurred in two cases; these were of low severity and improved following active treatment. During L-asparaginase treatment, a rash occurred in 29 patients and improved following symptomatic treatment; 25 of these patients were treated with pegaspargase subsequent to receiving positive results (detection of erythemas or wheals) from an L-asparaginase skin test. No treatment interruptions or treatment-associated mortality occurred in either group.

\section{Discussion}

ENKTL is a type of non-Hodgkin's lymphoma that accounts for $11 \%$ of lymphoma cases in China (3). Given the rapid course of clinical progression and relatively poor prognosis of ENKTL, the optimal treatment strategy for this disease remains unclear. Previously, either CHOP chemotherapy alone or radiotherapy alone was not able to achieve satisfactory results. Efficacy of the CHOP chemotherapy regimen for ENKTL is poor (26-29). Several studies have reported that radiotherapy is an important treatment method that is beneficial to local lesion control $(15,28,30,31)$. However, the rates of recurrence and distant metastasis were high, and the five-year survival rate was low in the early-stage patients who received radiotherapy alone $(28,32)$. As chemoradiotherapy strategies have progressed, chemotherapeutic regimens based on $\mathrm{CHOP}$-class anthracycline compounds have been reported (29). However, the efficacy remained low even following an increase in cyclophosphamide dose or the combination with other drugs such as semustine. In addition, these treatment regimens did not significantly improve patient survival in the early stages of ENKTL (30).

The insensitivity of ENKTL to conventional CHOP-class chemotherapy may be associated with tumor cell overexpression of P-glycoprotein, which is encoded by the MDR1 (33). Doxorubicin and vincristine, components of the CHOP-class treatment, may be actively pumped out by P-glycoprotein, thereby reducing the therapeutic effect. L-asparaginase hydrolyses asparaginase in the serum thereby reducing the levels of amino acids required in certain tumor cells that do not produce asparagine synthetase, resulting in the inhibition of DNA, RNA, and protein synthesis, which acts as an anti-tumor agent $(18,34)$. In vitro studies have demonstrated that asparaginase is able to reduce the activity of normal NK cells and induce apoptosis in NK tumor cells, whereas the conventional chemotherapy drugs used to treat lymphoma do not have this property $(35,36)$. Yong et al $(37)$ reported the use of an L-asparaginase-based treatment as the primary therapy for 11 patients with refractory midline peripheral T-cell lymphoma, and reported an efficacy of $63.6 \%$ and a two-year survival rate of $45.5 \%$. Subsequently, this L-asparaginase treatment was applied in 45 patients with relapsed or refractory ENKTCL and led to a CR rate of 56\%, an ORR of $82 \%$, and a five-year survival rate of $67 \%$ (19). A recent study on CHOP-L treatment combined with radiotherapy for newly diagnosed ENKTL demonstrated that, among 38 newly diagnosed patients with ENKTL who received CHOP-L chemotherapy and sequential radiotherapy, the CR rate was $81.6 \%$, the ORR rate was $84.2 \%$, and the two-year OS rate was $80.1 \%$ (23). The results of the present study demonstrated that, compared with the CHOP treatment group, the ENKTL patient group that received an L-asparaginase-based treatment combined with radiotherapy had significantly improved remission rate and improved long-term survival. Among the 112 patients in the L-asparaginase treatment group, the overall efficacy following two cycles of chemotherapy was $67.9 \%$, the overall efficacy at the end of the treatment was $90.18 \%$, the median OS duration was 77 months, the median PFS duration was 56 months, the one, two, and five-year OS rates were 96.0, 88.3 and $65.1 \%$, respectively, and the one, two, and five-year PFS rates were $94.2,79.8$ and $50.0 \%$, respectively.

The incidence of allergic reactions in patients who were treated with L-asparaginase has been reported to be $30 \%$ (38). Studies have reported that pegaspargase therapy had a similar efficacy to L-asparaginase as a treatment in children with acute lymphoblastic leukaemia $(39,40)$. In the present study, allergic reactions occurred in 29 patients in the asparaginase treatment group (25.9\%) during the application of L-asparaginase, and 25 of these patients $(22.3 \%)$ switched to treatment with pegaspargase following a positive L-asparaginase skin test results. The statistical results indicated that switching to pegaspargase did not affect the CR rate, OS, or PFS. A study on treatment with pegaspargase in newly diagnosed ENKTL patients is currently on-going in China. Pegaspargase may be another treatment option for ENKTL patients.

Prognostic factors that have been reported to be closely associated with ENKTL include patient age, B symptoms, ECOG score, regional lymph node invasion, clinical staging, $\mathrm{CR}$ rate, leukocytopenia, IPI score and Ki67 expression levels (41-43). In the present study, a univariate analysis of the 112 patients in the asparaginase regimen group demonstrated that patient age, clinical staging, IPI score, ECOG score, primary lesion site, LDH, leukocytopenia, Ki67 levels, and early treatment response affected patient OS and PFS $(\mathrm{P}<0.05)$. Other factors such as gender, $\mathrm{B}$ symptoms, and $\beta_{2}$-microglobulin had no impact on OS and PFS ( $\left.P>0.05\right)$. Multivariate analysis demonstrated that early treatment response $(\mathrm{P}<0.001)$, clinical staging $(\mathrm{P}<0.001)$, and $\mathrm{LDH}$ level $(\mathrm{P}=0.006)$ were independent predictors of $\mathrm{OS}$, whereas Ki67 expression levels $(\mathrm{P}=0.011)$, early treatment response $(\mathrm{P}=0.001)$, clinical staging $(\mathrm{P}=0.002)$, and $\mathrm{LDH}$ level $(\mathrm{P}=0.001)$ were independent predictors of PFS. 
In the present study the primary adverse reactions to treatment experienced by the patients in the two groups included bone marrow suppression, gastrointestinal reactions, infections, and liver dysfunction, most of which were rapidly relieved following symptomatic treatment. The incidence of hypofibrinogenemia was significantly higher in the asparaginase treatment group compared with the CHOP treatment group, although associated bleeding and thrombotic events occurred in only two cases and at a low severity, and no treatment-associated mortality was recorded.

In conclusion, L-asparaginase-based chemotherapy combined with radiotherapy is effective as a first-line treatment for ENKTL. The patients who received this type of treatment showed significantly increased improvements compared with those treated with the CHOP regimen combined with radiotherapy, with regard to short-term efficacy and long-term survival, as well as safety performance.

\section{Acknowledgements}

The present study was supported by grants from the National Natural Science Foundation of China (grant no. 81170520), the Henan Department of Health/Provincial Departmental collaboration project (grant no. 2011010014), and the National Natural Science Foundation of Henan Province (grant nos. 81170520 and 81000921).

\section{References}

1. Oshimi K: Progress in understanding and managing natural killer-cell malignancies. Br J Haematol 139: 532-544, 2007.

2. Suzuki R, Takeuchi K, Ohshima K and Nakamura S: Extranodal NK/T-cell lymphoma: Diagnosis and treatment cues. Hematol Oncol 26: 66-72, 2008.

3. Sun J, Yang Q, Lu Z, He M, Gao L, Zhu M, Sun L, Wei L, Li M, Liu C, et al: Distribution of lymphoid neoplasms in China: Analysis of 4,638 cases according to the world health organization classification. Am J Clin Pathol 138: 429-434, 2012.

4. Kim K, Kim WS, Jung CW, Im YH, Kang WK, Lee MH, Park $\mathrm{CH}$, Ko $\mathrm{YH}$, Ree HJ and Park K: Clinical features of peripheral T-cell lymphomas in 78 patients diagnosed according to the revised European-American lymphoma (REAL) classification. Eur J Cancer 38: 75-81, 2002.

5. Lee J, Park YH, Kim WS, Lee SS, Ryoo BY, Yang SH, Park KW, Kang JH, Park JO, Lee SH, et al: Extranodal nasal type NK/T-cell lymphoma: Elucidating clinical prognostic factors for risk-based stratification of therapy. Eur J Cancer 41: 1402-1408, 2005.

6. Chim CS, Ma SY, Au WY, Choy C, Lie AK, Liang R, Yau CC and Kwong YL: Primary nasal natural killer cell lymphoma: Long-term treatment outcome and relationship with the international prognostic index. Blood 103: 216-221, 2004.

7. Nakamura S, Katoh E, Koshikawa T, Yatabe Y, Nagasaka T, Ishida H, Tokoro Y, Koike K, Kagami Y, Ogura M, et al: Clinicopathologic study of nasal T/NK-cell lymphoma among the Japanese. Pathol Int 47: 38-53, 1997.

8. Takahashi N, Miura I, Chubachi A, Miura AB and Nakamura S: A clinicopathological study of 20 patients with T/natural killer (NK)-cell lymphoma-associated hemophagocytic syndrome with special reference to nasal and nasal-type NK/T-cell lymphoma. Int J Hematol 74: 303-308, 2001.

9. Chan JK, Sin VC,Wong KF, Ng CS, Tsang WY, Chan CH, Cheung MM and Lau WH: Nonnasal lymphoma expressing the natural killer cell marker CD56: A clinicopathologic study of 49 cases of an uncommon aggressive neoplasm. Blood 89: 4501-4513, 1997.

10. Kluin PM, Feller A, Gaulard P, Jaffe ES, Meijer CJ Müller-Hermelink HK and Pileri S: PeripheralT/NK-cell lymphoma: A report of the IXth Workshop of the European Association for Haematopathology. Histopathology 38: 250-270, 2001.
11. Al-Hakeem DA, Fedele S, Carlos R and Porter S: Extranodal NK/T-cell lymphoma, nasal type. Oral Oncol 43: 4-14, 2007.

12. Emile JF, Boulland ML, Haioun C, Kanavaros P, Petrella T, Delfau-Larue MH, Bensussan A, Farcet JP and Gaulard P: CD5-CD56+ T-cell receptor silent peripheral T-cell lymphomas are natural killer cell lymphomas. Blood 87: 1466-1473, 1996.

13. Attygalle AD, Cabeçadas J, Gaulard P, Jaffe ES, de Jong D, Ko YH, Said J and Klapper W: Peripheral T-cell and NK-cell lymphomas and their mimics; taking a step forward-report on the lymphoma workshop of the XVIth meeting of the European Association for Haematopathology and the society for Hematopathology. Histopathology 64: 171-199, 2014.

14. Kim GE, Cho JH, Yang WI, Chung EJ, Suh CO, Park KR, Hong WP, Park IY, Hahn JS, Roh JK and Kim BS: Angiocentric lymphoma of the head and neck: Patterns of systemic failure after radiation treatment. J Clin Oncol 18: 54-63, 2000.

15. Li YX, Yao B, Jin J, Wang WH, Liu YP, Song YW, Wang SL, Liu XF, Zhou LQ, He XH, et al: Radiotherapy as primary treatment for stage IE and IIE nasal natural killer/T-cell lymphoma. J Clin Oncol 24: 181-189, 2006.

16. Koom WS, Chung EJ, Yang WI, Shim SJ, Suh CO, Roh JK, Yoon JH and Kim GE: Angiocentric T-cell and NK/T-cell lymphomas: Radiotherapeutic viewpoints. Int J Radiat Oncol Biol Phys 59: 1127-1137, 2004.

17. Isobe K, Uno T, Tamaru J, Kawakami H, Ueno N, Wakita H, Okada J, Itami J and Ito H: Extranodal natural killer/T-cell lymphoma, nasal type: The significance of radiotherapeutic parameters. Cancer 106: 609-615, 2006.

18. Yamaguchi M, Kita K, Miwa H, Nishii K, Oka K, Ohno T, Shirakawa $S$ and Fukumoto $M$ : Frequent expression of P-glycoprotein/MDR1 by nasal T-cell lymphoma cells. Cancer 76: 2351-2356, 1995.

19. Yong W, Zheng W, Zhu J, Zhang Y, Wang X, Xie Y, Lin N, Xu B, $\mathrm{Lu} \mathrm{A}$ and Li J: L-asparaginase in the treatment of refractory and relapsed extranodal NK/T-cell lymphoma, nasal type. Ann Hematol 88: 647-652, 2009

20. Jaccard A, Petit B, Girault S, Suarez F, Gressin R, Zini JM, Coiteux V, Larroche C, Devidas A and Thiéblemont C: L-asparaginase-based treatment of 15 western patients with extranodal NK/T-cell lymphoma and leukemia and a review of the literature. Ann Oncol 20: 110-116, 2009.

21. Nagafuji K, Fujisaki T, Arima F and Ohshima K: L-asparaginase induced durable remission of relapsed nasal NK/T-cell lymphoma after autologous peripheral blood stem cell transplantation. Int J Hematol 74: 447-450, 2001.

22. Obama K, Tara M and Niina K: L-asparaginase-Based induction therapy for advanced extranodal NK/T-cell lymphoma. Int J Hematol 78: 248-250, 2003.

23. Lin N, Song Y,Zheng W, Tu M, Xie Y, Wang X, Ping L, Ying Z,Zhang $\mathrm{C}$, Deng L, et al: A prospective phase II study of L-asparaginaseCHOP plus radiation in newly diagnosed extranodal NK/T-cell lymphoma, nasal type. J Hematol Oncol 6: 44, 2013.

24. The International Non-Hodgkin's Lymphoma Prognostic Factors Project: A predictive model for aggressive non-Hodgkin's lymphoma. The International Non-Hodgkin's Lymphoma Prognostic Factors Project. N Engl J Med 329: 987-994, 1993.

25. Miller AB, Hoogstraten B, Staquet $M$ and Winkler A: Reporting results of cancer treatment. Cancer 47: 207-214, 1981.

26. Lee J, Kim WS, Park YH, Park SH, Park KW, Kang JH, Lee SS, Lee SI, Lee SH, Kim K, et al: Nasal-type NK/T cell lymphoma: Clinical features and treatment outcome. Br J Cancer 92: 1226-1230, 2005.

27. Kim BS, Kim TY, Kim CW, Kim JY, Heo DS, Bang YJ and Kim NK: Therapeutic outcome of extranodal NK/T-cell lymphoma initially treated with chemotherapy-result of chemotherapy in NK/T-cell lymphoma. Acta Oncol 42: 779-783, 2003.

28. Cheung MM, Chan JK, Lau WH, Ngan RK and Foo WW: Early stage nasal NK/T-cell lymphoma: Clinical outcome, prognostic factors, and the effect of treatment modality. Int J Radiat Oncol Biol Phys 54: 182-190, 2002.

29. Kim WS, Song SY, Ahn YC, Ko YH, Baek CH, Kim DY, Yoon SS, Lee HG, Kang WK, Lee HJ, et al: CHOP followed by involved field radiation: Is it optimal for localized nasal natural killer/T-cell lymphoma? Ann Oncol 12: 349-352, 2001.

30. Kim SJ and Kim WS: Treatment of localized extranodal NK/T cell lymphoma, nasal type. Int J Hematol 92: 690-696, 2010.

31. Wang ZY, Li YX, Wang WH, Jin J, Wang H, Song YW, Liu QF, Wang SL, Liu YP, Qi SN, et al: Primary radiotherapy showed favorable outcome in treating extranodal nasal-type NK/T-cell lymphoma in children and adolescents. Blood 114: 4771-4776, 2009. 
32. Li CC, Tien HF, Tang JL, Yao M, Chen YC, Su IJ, Hsu SM and Hong RL: Treatment outcome and pattern of failure in 77 patients with sinonasal natural killer/T-cell or T-cell lymphoma. Cancer 100: 366-375, 2004

33. Wang B, Li XQ, Ma X, Hong X, Lu H and Guo Y: Immunohistochemical expression and clinical significance of P-glycoprotein in previously untreated extranodal NK/T-cell lymphoma, nasal type. Am J Hematol 83: 795-799, 2008.

34. Chaudhary PM, Mechetner EB and Roninson IB: Expression and activity of the multidrug resistance P-glycoprotein in human peripheral blood lymphocytes. Blood 80: 2735-2739, 1992.

35. Charamella LJ, Meyer C, Thompson GE and Dimitrov NV: Chemotherapeutic agents and modulation of natural killer cell activity in vitro. J Immunopharmacol 7: 53-65, 1985.

36. Ando M, Sugimoto K, Kitoh T, Sasaki M, Mukai K, Ando J, Egashira M, Schuster SM and Oshimi K: Selective apoptosis of natural killer-cell tumours by l-asparaginase. Br J Haematol 130: 860-868, 2005.

37. Yong $\mathrm{W}, \mathrm{Zhang} \mathrm{Y}$ and Zheng $\mathrm{W}$ : The efficacy of L-asparaginase in the treatment of refractory midline peripheral T-cell lymphoma. Zhong Hua Xue Ye Xue Za Zhi 21: 577-579, 2000 (In Chinese).

38. Silverman LB, Supko JG, Stevenson KE, Woodward C, Vrooman LM, Neuberg DS, Asselin BL, Athale UH, Clavell L, Cole PD, et al: Intravenous PEG-asparaginase during remission induction in children and adolescents with newly diagnosed acute lymphoblastic leukemia. Blood 115: 1351-1353, 2010.
39. Avramis VI, Sencer S, Periclou AP, Sather H, Bostrom BC, Cohen LJ, Ettinger AG, Ettinger LJ, Franklin J, Gaynon PS, et al: A randomized comparison of native Escherichia coli asparaginase and polyethylene glycol conjugated asparaginase for treatment of children with newly diagnosed standard-risk acute lymphoblastic leukemia: A Children's cancer group study. Blood 99: 1986-1994, 2002.

40. Cooperation Group of Phase II Clinical Trial of PEG-Asp: Comparison of polyethylene glycol conjugated asparaginase and L-asparaginase for treatment of childhood acute lymphoblastic leukemia. Zhong Hua Xue Ye Xue Za Zhi 29: 29-33, 2008 (In Chinese.)

41. Kim YR, Kim JS, Kim SJ, Jung HA, Kim SJ, Kim WS, Lee HW, Eom HS, Jeong SH, Park JS, et al: Lymphopenia is an important prognostic factor in peripheral T-cell lymphoma (NOS) treated with anthracycline-containing chemotherapy. J Hematol Oncol 4: 34, 2011.

42. Chauchet A, Michallet AS, Berger F, Bedgedjian I, Deconinck E, Sebban C, Antal D, Orfeuvre H, Corront B, Petrella T, et al: Complete remission after first-line radio-chemotherapy as predictor of survival in extranodal NK/T cell lymphoma. J Hematol Oncol 5: 27, 2012.

43. Kim SJ, Kim BS, Choi CW, Choi J, Kim I, Lee YH and Kim JS $\mathrm{Ki}-67$ expression is predictive of prognosis in patients with stage I/II extranodal NK/T-cell lymphoma, nasal type. Ann Oncol 18: 1382-1387, 2007. 